\title{
Variation in Levels of Flavonols Myricetin, Quercetin and Kaempferol-In Kenyan Tea (Camellia sinensis L.) with Processed Tea Types and Geographic Location
}

\author{
Simon Mwangi Kingori, Simon Oduor Ochanda, Robert Kipyegon Koech \\ Kenya Agricultural and Livestock Research Organization, Tea Research Institute (KALRO), Kericho, Kenya \\ Email: smkingori@gmail.com
}

How to cite this paper: Kingori, S.M., Ochanda, S.O. and Koech, R.K. (2021) Variation in Levels of Flavonols Myricetin, Quercetin and Kaempferol-In Kenyan Tea (Camellia sinensis L.) with Processed Tea Types and Geographic Location. Open Journal of Applied Sciences, 11, 736-749.

https://doi.org/10.4236/ojapps.2021.116054

Received: April 23, 2021

Accepted: June 26, 2021

Published: June 29, 2021

Copyright $\odot 2021$ by author(s) and Scientific Research Publishing Inc. This work is licensed under the Creative Commons Attribution International License (CC BY 4.0).

http://creativecommons.org/licenses/by/4.0/

\begin{abstract}
The aim of this study was to determine the levels of myricetin, quercetin, and kaempferol in green and black Kenyan types in relation to geographic location of production. Tea samples were extracted before chromatographic separations with a Shimadzu 20A HPLC coupled with PDA. Flavonol levels were quercetin $>$ kaempferol $>$ myricetin. Teas from east of rift, had quercetin $1.25-1.83 \mathrm{mg} / \mathrm{g}$ and $1.29-1.71 \mathrm{mg} / \mathrm{g}$ for green and black types, respectively. Kaempferol levels were between $1.28-1.72 \mathrm{mg} / \mathrm{g}$ in green and $1.36-1.76$ $\mathrm{mg} / \mathrm{g}$ in black tea. Myricetin ranged at $0.40-0.79 \mathrm{mg} / \mathrm{g}$ green and $0.12-0.38$ $\mathrm{mg} / \mathrm{g}$ black tea types. Total flavonols in green tea were highest at $4.28 \mathrm{mg} / \mathrm{g}$ while black tea was $3.83 \mathrm{mg} / \mathrm{g}$. These trends agree well with those observed in teas west of the rift. For tea types, myricetin and kaempferol showed a significant difference $(\mathrm{P} \leq 0.05)$ between green and black teas. Total flavonols showed no significant difference. Kenyan teas are a potential dietary source of flavonols myricetin, quercetin, and kaempferol as evidenced by the significant quantities recorded in this study.
\end{abstract}

\section{Keywords}

Samples, Extracted, Chromatographic, Separations

\section{Introduction}

Tea (Camellia sinensis) is a beverage consumed hot or iced for both refreshment and health benefits since ancient times [1]. The beverage is derived from tender tea shoots that contain a full complement of enzymes, biochemical interme- 
diates, carbohydrates, proteins and lipids [2]. The tea shoot is distinguished by its remarkable content of polyphenols and methyl xanthine-caffeine, theobromine and theophylline [3]. Tea biochemicals have gained popularity as ingredients in dietary supplements and functional foods. Of particular interest are the catechins, which are regarded as the most useful components of tea due to being associated with health benefits, antioxidant and sensory properties [4]. Twelve catechins including epicatechin (EC), epigallocatechin (EGC), epicatechin gallate (ECG) and epigallocatechin gallate (EGCG); four of their epimers at the C-2 position, simple catechin $(+C)$, gallocatechin $(\mathrm{GC})$, catechin gallate $(\mathrm{CG})$ and gallocatechin gallate (GCG); and four methylated catechin derivatives, epigallocatechin-3-O-(3-O-methyl)gallate, gallocatechin-3-O-(3-O-methyl)gallate, epigallocatechin-3-O-(4-O-methyl)gallate and epicatechin-3-O-(3-O-methyl)gallate have been identified by chromatography [5]. However, only eight have been shown to be present in tea in significant quantities [6]. Furthermore, previous studies focused specifically on the most abundant catechins epigallocatechin gallate (EGCG) and epigallocatechin (EGC), which constitute more than $70 \%$ of the total amount of all catechins [7] [8]. Caffeine a central nervous system (CNS) stimulant of the methyl xanthine class is odorless, has a bitter taste and is highly soluble in hot water. Additionally, processed tea leaves contain $3 \%$ caffeine by weight, although this can range from $1.4 \%$ to $4.5 \%$. Consumption of caffeine has overtime elicited health concerns. However, adverse health impacts to humans depend on factors such as the levels and rate of consumption as well as mental and physical health conditions [9] [10]. Green tea extracts (GTEs) are common ingredients among dietary supplements marketed for weight loss and management [11]. Furthermore, like diet and exercise, they play important roles in ameliorating metabolic syndrome [12].

Besides the polyphenols and alkaloids, tea has a complex chemical composition, containing over 2000 components that include, carotenoids, lignans, amino acids (including L-theanine), vitamins, minerals and trace elements [13]. Although mankind has been drinking tea for more than 5000 years, determination of its chemical composition has not been intensive until recent decades after abundance of scientific data has shown a positive effect of tea on human health [14] [15]. Flavonol glycosides in tea leaves have been quantified as aglycones-myricetin, quercetin, and kaempferol [16]. Figure 1 shows the chemical structures of myricetin, quercetin, and kaempferol.<smiles>COc1cc(O)cc2oc(-c3cc(O)c(O)c(O)c3)c(O)c(=O)c12</smiles>

Figure 1. Chemical structures of flavonols myricetin, quercetin and kaempferol. 
Presence of myricetin, quercetin, and kaempferol has been reported in fruits and vegetables for a long time [17]. Furthermore, these aglycones are also found in abundance in onions, grapes, berries, cherries, broccoli, and citrus fruits, possess protective abilities against tissue injury induced by various drug toxicities [18] [19] [20]. Additionally, are important bioflavonoids having beneficial effects which include cardiovascular protection, anticancer, antitumor, anti-ulcer, anti-allergy, anti-viral, anti-inflammatory activity, anti-diabetic, gastro protective effects, antihypertensive, and immunomodulatory [21] [22] [23]. Documented data in literature on flavonols and their glycosides in tea is scanty suggesting an existing gap in this area of research [24] [25]. This study aims at determining the flavonol content in both green and processed Cut, Tear and Curl (CTC) black tea collected from all the seven tea growing regions of Kenya as categorized by the Kenya Tea Development Agency (KTDA). The Kenya Tea Development Agency has subdivided the regions as Aberdare ranges (1 and 2), Mt Kenya (3), Mt Kenya and Nyambene hills (4), Kericho highlands (5), Kisii highlands (6) and Nandi hills and Western highlands (7) [26] [27] which are predominantly in the eastern (Mt Kenya region) and western (Lake Victoria basin) sides of the great rift valley. It is importantly mentioned here that apigenin, the only flavone identified in tea, and its glycosides, have also been detected in tea however, as very small fraction of the tea polyphenols. More recently, $19 O$-glycosylated flavonols, $7 C$-glycosylated flavones, 28 acylated glycosylated flavonols, and 3 flavonols have been identified from green and fermented teas using liquid chromatography.

The processed teas including; white tea, yellow tea, green tea, Oolong tea, black tea, purple tea and post fermented tea which are subjected to varying processing conditions in order to attain specific levels of oxidation. For green tea, leaves are plucked, steamed and dried to stop enzymatic activities that cause oxidation while the black tea is allowed to undergo the enzymatic oxidation process supported by polyphenol oxidase inherent in tea leaves. Studies have shown that biochemical compositions of teas sourced from the different regions have distinct levels identifiable with that specific regions [28]. Composition of the same type of tea may vary significantly depending on the place where it was grown mainly due to the cultivar type, soil, climate, altitude and precipitation patterns [29]. The other factors are agronomic practice, processing technologies used and how well the finished products are stored [30]. According to a research conducted by Muthumani et al; 2013 altitude significantly affected the catechin composition of green tea leaves [31]. In another study, black teas from higher altitude showed higher levels of theaflavins and aroma composition while crude fibre remained unchanged by variations in altitude [32] [33].

In analysis of plant composition, several challenges are normally encountered mainly due to the chemical complexity in the plant matrix and the physical nature of the plant materials [34]. High-temperature liquid-solid extraction is mostly applied to isolate the targeted biochemicals to be determined [35]. Other 
extraction methods that have been used include, ultrasonic, microwave-assisted, solid-liquid extraction at ambient temperature, and elevated pressure supercritical extraction with carbon dioxide [36]. Solvents, such as chloroform, methanol, ethanol and acetone or mixtures of these and water are used for extraction [37]. For identification of the extracted aglycones, preparative thin layer chromatography (TLC), reverse phase-high performance liquid chromatograph (RP-HPLC), micellar liquid chromatography and gas chromatograph coupled mass spectrometer (GC-MS) are used [38] [39]. The data generated in this study will be used as a pointer to the potency of the Kenyan tea as dietary source of flavonol glycoside aglycones of quercetin, myricetin, and kaempferol which are versatile antioxidants. Moreover, unique levels of these biochemicals ascertained in specific tea cultivars can lead to development of specialty tea products a milestone in value addition chain and product diversification.

\section{Materials and Methods}

\subsection{Tea Samples}

Green tea leaves were sourced from farmers in the seven Kenya Tea Development Agency (KTDA) zoned regions (Aberdare ranges (1 and 2), Mt Kenya (3), Mt Kenya and Nyambene hills (4), Kericho highlands (5), Kisii highlands (6) and Nandi hills and Western highlands (7)). In each of the regions two catchment areas were randomly identified for sample collection with sampling being done in triplicate. All the samples were well packed in brown aluminium lined bags ready for laboratory determinations.

\subsection{Reagents and Chemicals}

Acetonitrile, acetic acid (both HPLC grade), hydrochloric acid, methanol, ethanol (both of analytical grade), the standards of quercetin, kaempferol and myricetin were purchased from Sigma-Aldrich (Germany) through Kobian suppliers. Double distilled water was prepared in the laboratory.

\subsection{Sample Preparation}

\subsubsection{Preparation of Test Samples}

To ensure homogeneity, the samples were ground in accordance to ISO 1572 [40] recommendations and stored in well-sealed containers for protection against light to avoid oxidation of the biochemicals and weakened aroma.

\subsubsection{Determination of Dry Matter Content}

$2.0 \pm 0.01 \mathrm{~g}$ of the sample was weighed into aluminium dishes and heated in an oven at $103^{\circ} \mathrm{C} \pm 2.0^{\circ} \mathrm{C}$ for 4 hours to obtain constant weight. The samples were weighed again and moisture content determined by subtracting the final weight from the initial weight, computed and expressed as a percent.

\subsubsection{Extraction of Flavonols Myricetin, Quercetin and Kaempferol}

$1 \mathrm{~g}$ of well powdered tea leave sample was weighed into a $250 \mathrm{~mL}$ round bot- 
tomed flask. $40 \mathrm{~mL}$ of $60 \%$ aqueous methanol was added followed by $5 \mathrm{~mL}$ of $6 \mathrm{M}$ hydrochloric acid (HCL). The mixture was refluxed for 2 hours at the boiling temperature before filtering in a $50 \mathrm{~mL}$ volumertric flask. On cooling, the filtrate was made to mark with $60 \%$ methanol in water. A $0.45 \mu$ membrane filter was used to filter the sample before injecting into the HPLC.

\subsection{Standards Preparation}

$200 \mu \mathrm{g} / \mathrm{mL}$ stock solutions each of myricetin, quercetin, and kaempferol were prepared at in ethanol at room temperature $\left(20^{\circ} \mathrm{C}-25^{\circ} \mathrm{C}\right)$. Working standard solutions for each of the individual standards were diluted in the range of 0 - 100 $\mu \mathrm{g} / \mathrm{mL}$ and passed through a $0.45 \mu$ filter membrane before injecting into the HPLC.

\subsection{HPLC Instrumentation and Conditions}

The HPLC system Shimadzu LC 20 A series consisted of binary pump with vacuum degasser (DGU-20A $\mathrm{A}_{5 \mathrm{R}}$ ), thermostated column compartment (CTO-10AS $\mathrm{vp}$ ), auto sampler (SIL $20 \mathrm{AT}_{\mathrm{HT}}$ ), photo diode array detector (SPD-20MA) all from Shimadzu Corporation, Kyoto in Japan. $\mathrm{A} \mathrm{C}_{18}$-phenyl reversed-phase column $(4.6 \times 250 \mathrm{~mm}, 5 \mu)$ was used and the column temperature maintained at $25^{\circ} \mathrm{C}$. The mobile phase composition consisted of $0.1 \%$ aqueous acetic acids mobile phase A and acetonitrile-HPLC grade as mobile phase B. A gradient elution system was run at the time $0.01 \mathrm{~min} 10 \% \mathrm{~B} ; 30 \mathrm{~min} 55 \% \mathrm{~B} ; 35 \mathrm{~min} 50 \% \mathrm{~B} ; 38$ - 40 $\min 10 \% \mathrm{~B}$. The mobile phase flow rate was $1.0 \mathrm{~mL} / \mathrm{min}$ and the injection volume was $20 \mu \mathrm{L}$. The eluents were detected and analyzed at $370 \mathrm{~nm}$.

\subsection{Statistical Analysis of Data}

All statistical analysis was carried out using SAS ${ }^{\circ}$ V 9.1 (SAS.2002) for windows statistical software. Analysis of variance (ANOVA) was used to determine the means, coefficient of variation (CV) and any differences between the samples. Least Significance Difference (LSD) was used to separate means. The probability limit was set at $\mathrm{P} \leq 0.05$ significant level. Results of the parameter determined were expressed as a mean of the triplicate determinations. Graphical representation of means was done using excel for windows.

\section{Results and Discussion}

\subsection{Quantitative Levels of Myricetin, Quercetin and Kaempferol in Kenyan Tea}

Flavonoids are a group of plant secondary metabolites characterized by a diphenyl propane structure $\left(\mathrm{C}_{6}-\mathrm{C}_{3}-\mathrm{C}_{6}\right)[41]$ and are common constituents of fruits, vegetables and some beverages [42]. The major flavonols present in tea leaves hardly exceeds $3 \%$ of the water-soluble solids in tea [43]. The current study has made an attempt to determine the levels of myricetin, quercetin, kaempferol and total flavonol in green and black tea types sourced from different tea growing re- 
gions in the east and west of the great rift valley in Kenya. The levels of these biochemicals in Kenyan tea have little been reported if at all and hence the need for their profiling across all the tea growing regions of the country. Additionally, the potential of the Kenyan tea as dietary and nutraceutical source of the flavonols need be established. Figure 2 and Figure 3 show the levels of myricetin, quercetin, kaempferol and total flavonol in Kenyan tea.

The major flavonols were detected in all the teas and eluted in the order myricetin (24.262 $\mathrm{min}$ ), quercetin (27.295 $\mathrm{min}$ ) and kaempferol (30.195 min) under the chromatographic conditions of the study (Figure 4). Quantitatively, the flavonols were in the order quercetin $>$ kaempferol $>$ myricetin indicating that quercetin was the most dominant of the three biomolecules. This findings are in line with work done by Kicel and Olszewska, 2015 [44], however, in some

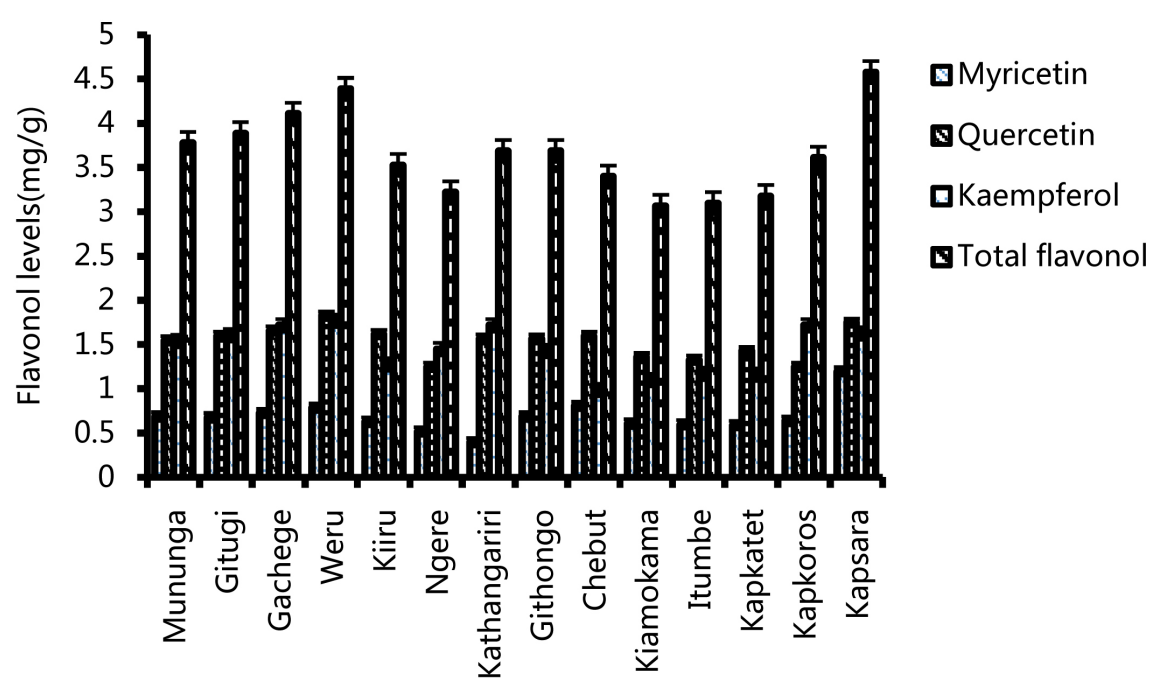

Figure 2. Flavonols content in green tea from selected field sites in east and west of rift (mg/g, dry matter).

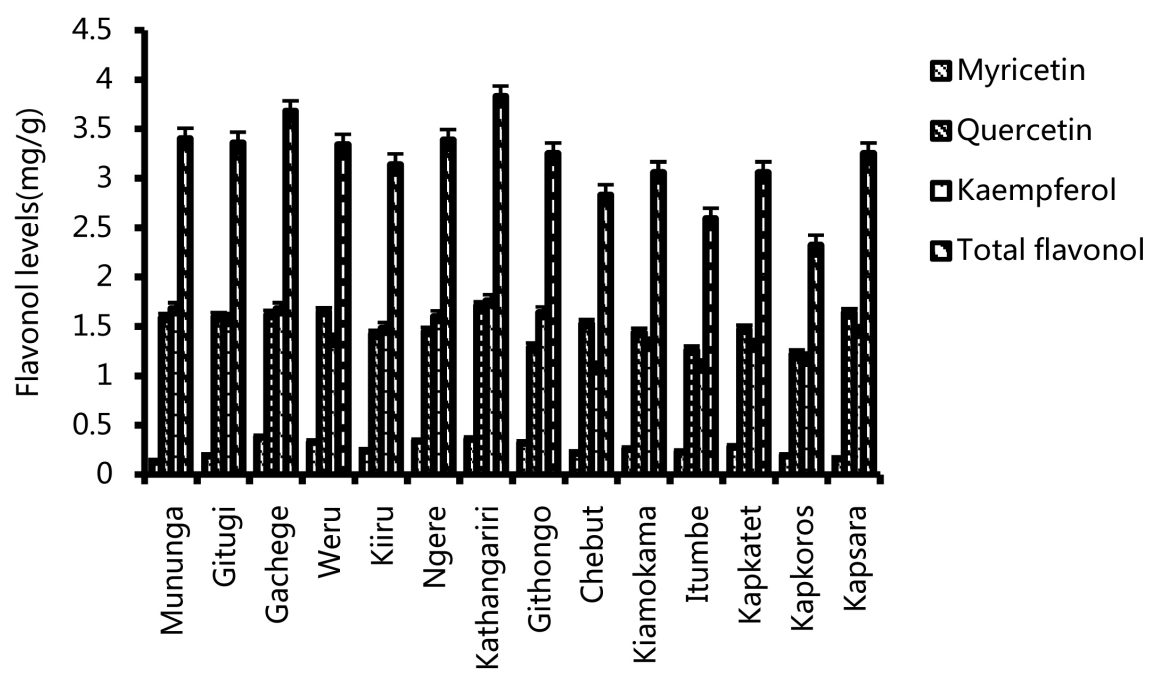

Figure 3. Flavonols content in black tea from selected KTDA factories in east and west of rift (mg/g, dry matter). 


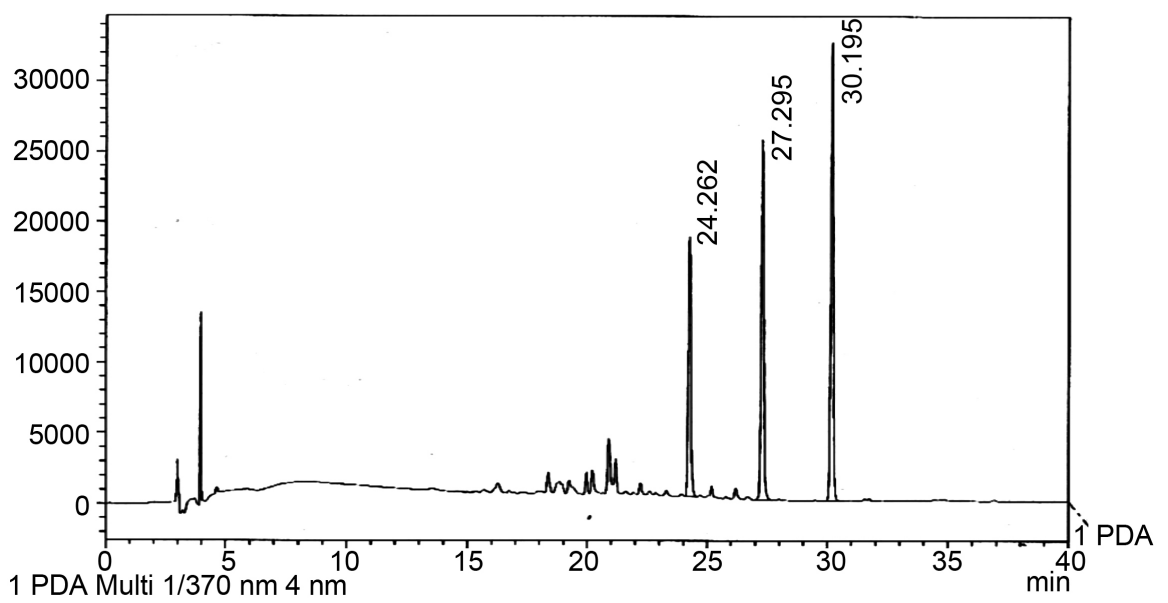

Figure 4. A typical HPLC chromatogram of a tea sample: myricetin (24.262 min); quercetin (27.295 $\mathrm{min})$; kaempferol (30.195 $\mathrm{min})$.

instances, especially for teas in the east of rift, kaempferol a health enhancing biochemical was predominant amongst the three flavonols. This finding elicit much interest for follow up research given that epidemiological studies have shown possible association between the consumption of foods containing kaempferol and a reduced risk of developing several disorders, including cancer and cardiovascular diseases [45]. The teas sourced from the east of rift, quercetin levels ranged at $1.25-1.83 \mathrm{mg} / \mathrm{g}$ and $1.29-1.71 \mathrm{mg} / \mathrm{g}$ for green and black tea types respectively. Kaempferol levels were $1.28-1.72 \mathrm{mg} / \mathrm{g}$ in green and $1.36-1.76$ $\mathrm{mg} / \mathrm{g}$ in black tea. Myricetin was the least abundant at the ranges of $0.40-0.79$ $\mathrm{mg} / \mathrm{g}$ and $0.12-0.38 \mathrm{mg} / \mathrm{g}$ green and black tea types respectively. For green tea, the highest levels for total flavonol, a sum of levels of myricetin, quercetin and kaempferol, was $4.28 \mathrm{mg} / \mathrm{g}$ and $3.83 \mathrm{mg} / \mathrm{g}$ in black tea. The trends highlighted here are similar to those observed for green and black teas in the west of the rift as demonstrated. These results compare well with that reported for flavonols content of beverage of the Sri Lankan tea germplasm [46]. Furthermore, other researchers Peterson et al. working on green tea [47] and Luximon-Rammaetal on black tea [48] reported on levels of flavonols that to a greater extend are in agreement with the findings of the study.

\subsection{Effects of Processing on Levels of Myricetin, Quercetin and Kaempferol in Kenyan Tea}

The phytochemical composition of tea leaves is affected by factors such as the growing regions, climatic conditions, cultivars, brewing techniques, agronomic practices and processing conditions [49]. It has been observed that in leaf processing, levels of catechins and polyphenols increase slightly during the withering stage. In black tea manufacture there is a higher loss of catechins due to the conversion of phenolic compounds to theaflavins and thearubigins. In general, fermentation is one of the stages in processing that much emphasis is focused aimed at changing the ingredients in agro-food processing [50]. Figure 5 


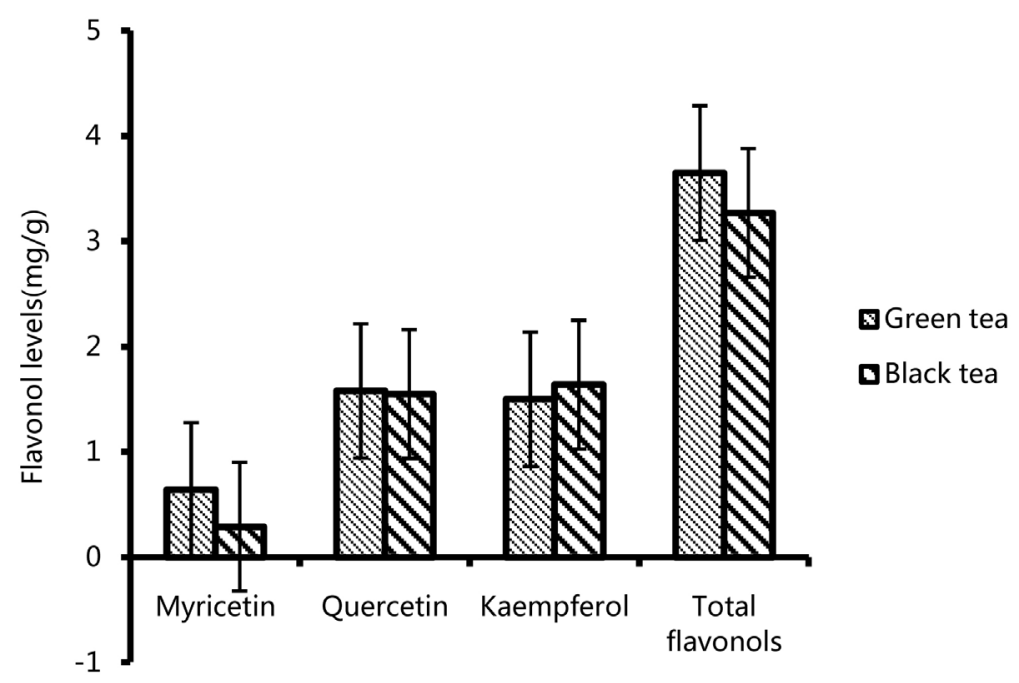

Figure 5. Combined means for green and black teas $(\mathrm{mg} / \mathrm{g}$, dry matter) for east and west of rift.

shows means of the levels flavonols myricetin, quercetin and kaempferol in both green and black teas.

The means for myricetin in black and green teas showed significant difference while those for quercetin and total flavonols were not significantly different. The means for kaempferol were significantly different at $1.50 \mathrm{mg} / \mathrm{g}$ for green and $1.64 \mathrm{mg} / \mathrm{g}$ for black teas. Two researchers have in the past given conflicting findings on changes in the levels of total flavonols during black tea processing. Del Rio et al. reported that about 30\% reduction in total flavonols is recorded during black tea processing [51] while Zhao et al. observed that flavonol contents were not affected by the degrees of fermentation on transiting from green to pu'er tea products [52]. There is no or little if at all documented research findings focusing on the changes of flavonols during various tea processing stages. Hence, there is need to optimize processing conditions to maximize on retention of flavonols (myricetin, quercetin and kaempferol) which have been reported to be important food supplements possessing anti-oxidative, anti-inflammatory, and anticancer properties. Myricetin in this study was the flavonol that varied the most and was lowest in black tea suggesting that due to processing, different tea products may have different quantities of myricetin. This finding compliment what has previously been reported in literature.

\subsection{Variation on Levels of Myricetin, Quercetin and Kaempferol in Kenyan Tea with Geographic Location}

The composition of bioactive compounds, as already highlighted, might be influenced by several parameters associated with plant growth. Additional factors include, genetics train, climatic conditions, soil profile, growth altitude and plucking season [53]. Studies have demonstrated that higher elevation is associated with higher tea quality based on levels of catechins, other polyphenols and caffeine [45]. It is reported that there is increase in favorable aromatic compounds 


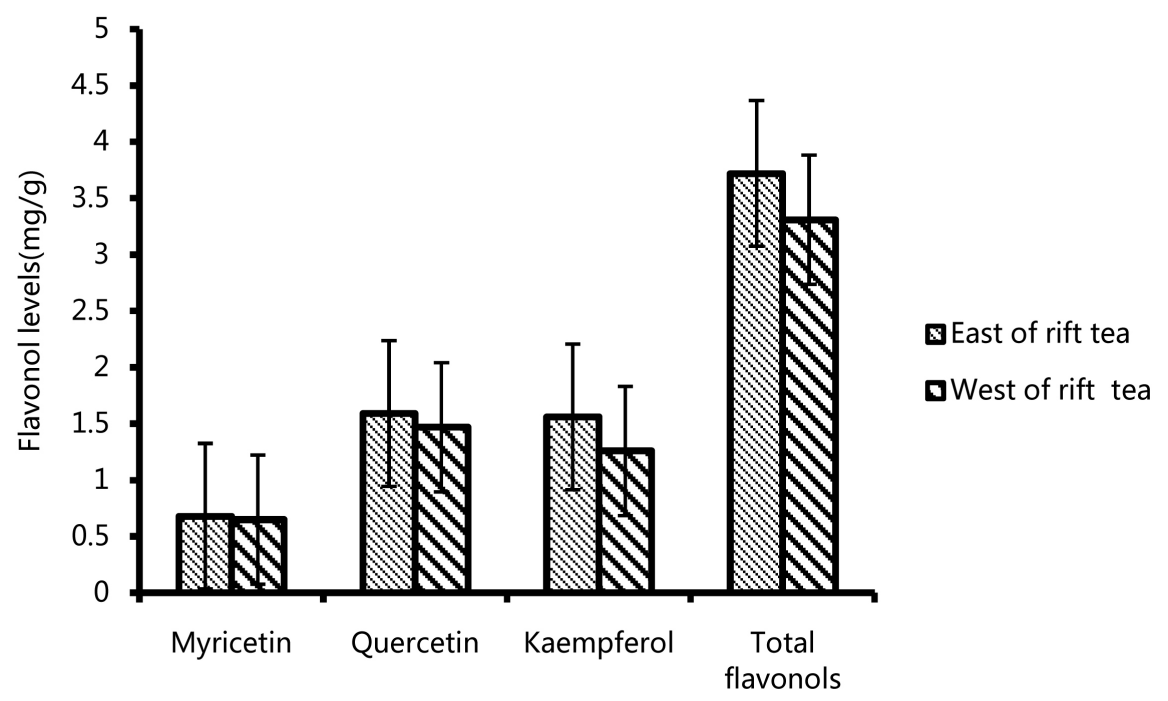

Figure 6. Means for green teas in the east and west of rift.

that have sweet, floral, and honey-like notes with an increase in elevation while decreases in caffeine, epicatechin gallate, gallocatechin, and catechin are exhibited [54]. Figure 6 shows means of the levels flavonols myricetin, quercetin and kaempferol in teas sourced from the east and west of rift, regions considered having varied altitudes.

The flavonols myricetin and quercetin had means that were not significantly different for teas sourced from the east and west of rift regions while kaempferol and total flavonols had means that varied significantly at $\mathrm{P} \leq 0.05$. Literature on the variation of myricetin, quercetin and kaempferol in tea with altitude is scanty and hence there is need for detailed research in this area with an aim of generating flavonol rich tea products as a means of optimizing quality. Furthermore, data generated can be used as a guide in identification of the origin of Kenyan tea given the variations in the geography of the two regions. The east of rift is a region which is predominantly around the Aberdare ranges and the Mt Kenya region with elevations of 1500 - 2200 meters above the sea level while the west of rift lies in the Lake Victoria basin at heights of 1500 - 2150 meters above sea level [55].

\section{Conclusion}

Myricetin, quercetin, and kaempferol have been found in significant amounts in both green and black Kenyan tea types sourced from the east and west of rift valley tea growing regions. The green tea had higher levels of myricetin than the black tea, while those of kaempferol were significantly lower. The levels of quercetin, and total flavonol were not significantly different. The total flavonol levels between the east and west of rift valley tea growing regions were significantly different suggesting regional variations on the contents of the flavonols. The significant amounts of flavonols myricetin, quercetin, and kaempferol, which are potent antioxidants with health-promoting aspects, are supportive of Kenyan tea 
as a potential nutraceutical product as well as a dietary source of the flavonols. Additionally, the flavonol profile can be effectively used as a mark of origin for the high quality Kenyan tea products. Given that Kenyan teas have shown great potential as sources of the flavonol myricetin, quercetin and kaempferol, there is a need to carry out further research to establish the content of these biochemicals in known superior Kenyan tea cultivars especially the newly released types that score high in quality and yields. This will include cultivars such as TRFK 6/8, Ejulu, EPK-TN14-3, AHP S15/10, TRFK 91/1, TRFK 597/4, TRFK 660/1, TRFK 895/17, TRFK 914/11, TRFK 914/28, TRFK 914/39, D99/10, TRFK 301/5, TRFK 895/7, TRFK 306/1, TRFK 306/2 TRFK 306/3 and TRFK 306/4.

\section{Acknowledgements}

1) Kenya Agricultural and Livestock Research Organization-Tea Research Institute, especially the Tea Processing and Value Addition (TPVA) laboratory where analysis was carried out. 2) National Research Fund (NRF).

\section{Competing Interests}

The authors declare that there is no conflict of interests regarding the publication of this paper.

\section{References}

[1] Aboulwafa, M.M., Youssef, F.S., Gad, H.A., Altyar, A.E., Al-Azizi, M.M. and Ashour, M.L. (2019) A Comprehensive Insight on the Health Benefits and Phytoconstituents of Camellia sinensis and Recent Approaches for Its Quality Control. Antioxidants, 8, Article No. 455. https://doi.org/10.3390/antiox8100455

[2] Ahmed, S. and Stepp, J.R. (2013) Green Tea: The Plants, Processing, Manufacturing and Production. In: Preedy, V.R., Ed., Tea in Health and Disease Prevention, Academic Press, Waltham, 19-31. https://doi.org/10.1016/B978-0-12-384937-3.00002-1

[3] Mohanpuria, P., Kumar, V. and Yadav, S.K. (2010) Tea Caffeine: Metabolism, Functions, and Reduction Strategies. Food Science and Biotechnology, 19, 275-287. https://doi.org/10.1007/s10068-010-0041-y

[4] Shahidi, F. and Ambigaipalan, P. (2015) Phenolics and Polyphenolics in Foods, Beverages and Spices: Antioxidant Activity and Health Effects-A Review. Journal of Functional Foods, 18, 820-897. https://doi.org/10.1016/j.jff.2015.06.018

[5] Teixeira, N.do.C.V. (2015) Study of Prodelphinidins: Synthesis, Detection, Identification and Reactivity with Anthocyanins.

[6] Guillarme, D., Casetta, C., Bicchi, C. and Veuthey, J.-L. (2010) High Throughput Qualitative Analysis of Polyphenols in Tea Samples by Ultra-High Pressure Liquid Chromatography Coupled to UV and Mass Spectrometry Detectors. Journal of Chromatography $A, 1217,6882-6890$. https://doi.org/10.1016/j.chroma.2010.08.060

[7] Machu, L., Misurcova, L., Vavra Ambrozova, J., Orsavova, J., Mlcek, J., Sochor, J., et al. (2015) Phenolic Content and Antioxidant Capacity in Algal Food Products. Molecules, 20, 1118-1133. https://doi.org/10.3390/molecules20011118

[8] Singh, M., Arseneault, M., Sanderson, T., Murthy, V. and Ramassamy, C. (2008) Challenges for Research on Polyphenols from Foods in Alzheimer's Disease: Bioavailability, Metabolism, and Cellular and Molecular Mechanisms. Journal of Agri- 
cultural and Food Chemistry, 56, 4855-4873. https://doi.org/10.1021/jf0735073

[9] dePaula, J. and Farah, A. (2019) Caffeine Consumption through Coffee: Content in the Beverage, Metabolism, Health Benefits and Risks. Beverages, 5, Article No. 37. https://doi.org/10.3390/beverages5020037

[10] Onaolapo, O. J. and Onaolapo, A.Y. (2019) Caffeinated Beverages, Behavior, and Brain Structure. In: Mihai Grumezescu, A. and Maria Holban, A., Eds., Caffeinated and Cocoa Based Beverages, Vol. 8, Woodhead Publishing, Cambridge, 163-207. https://doi.org/10.1016/B978-0-12-815864-7.00005-2

[11] Kortubash, I., Ewing, L., Skinner, C., Nookaew, I., Avula, B., Khan, I., et al. (2020) Green Tea Extract as a Safe and Effective Dietary Supplement: Lessons Learned from Mice. Current Developments in Nutrition, 4, 419.

https://doi.org/10.1093/cdn/nzaa045_052

[12] Navarro, V.J., Khan, I., Björnsson, E., Seeff, L.B., Serrano, J. and J. Hoofnagle, H. (2017) Liver Injury from Herbal and Dietary Supplements. Hepatology, 65, 363-373. https://doi.org/10.1002/hep.28813

[13] Chaturvedula, V.S.P. and Prakash, I. (2011) The Aroma, Taste, Color and Bioactive Constituents of Tea. Journal of Medicinal Plants Research, 5, 2110-2124.

[14] Pan, M.-H., Tung, Y.-C., Yang, G., Li, S. and Ho, C.-T. (2016) Molecular Mechanisms of the Anti-Obesity Effect of Bioactive Compounds in Tea and Coffee. Food \& Function, 7, 4481-4491. https://doi.org/10.1039/C6FO01168C

[15] Di Lorenzo, A., Curti, V., Tenore, G.C., Nabavi, S.M. and Daglia, M. (2017) Effects of Tea and Coffee Consumption on Cardiovascular Diseases and Relative Risk Factors: An Update. Current Pharmaceutical Design, 23, 2474-2487. https://doi.org/10.2174/1381612823666170215145855

[16] Brodowska, K.M. (2017) Natural Flavonoids: Classification, Potential Role, and Application of Flavonoid Analogues. European Journal of Biological Research, 7, 108-123.

[17] Garcia-Salas, P., Morales-Soto, A., Segura-Carretero, A. and Fernández-Gutiérrez, A. (2010) Phenolic-Compound-Extraction Systems for Fruit and Vegetable Samples. Molecules, 15, 8813-8826. https://doi.org/10.3390/molecules15128813

[18] Alvarez, A.I., Real, R., Pérez, M., Mendoza, G., Prieto, J.G. and Merino, G. (2010) Modulation of the Activity of ABC Transporters (P-Glycoprotein, MRP2, BCRP) by Flavonoids and Drug Response. Journal of Pharmaceutical Sciences, 99, 598-617. https://doi.org/10.1002/jps.21851

[19] Hrelia, S., Angeloni, C., Watson, R. and Preedy, V. (2012) Quercetin and Its Metabolites in Heart Health. In: Ross Watson, R. and Preedy, V.R., Eds., Bioactive Food as Dietary Interventions for Cardiovascular Disease, Academic Press, Waltham, 217-228. https://doi.org/10.1016/B978-0-12-396485-4.00011-6

[20] Mir, I.A. and Tiku, A.B. (2015) Chemopreventive and Therapeutic Potential of "Naringenin," a Flavanone Present in Citrus Fruits. Nutrition and Cancer, 67, 27-42. https://doi.org/10.1080/01635581.2015.976320

[21] David, A.V.A., Arulmoli, R. and Parasuraman, S. (2016) Overviews of Biological Importance of Quercetin: A Bioactive Flavonoid. Pharmacognosy Reviews, 10, 84-89. http://dx.doi.org/10.4103/0973-7847.194044

[22] Xuan, T.D. and Khanh, T.D. (2016) Chemistry and Pharmacology of Bidens pilosa: An Overview. Journal of Pharmaceutical Investigation, 46, 91-132. https://doi.org/10.1007/s40005-016-0231-6

[23] Gaikwad, S.A. (2018) Phytochemical Investigation of Bioactive Emodin and Quercetin in Cassia fistula and Cassia tora Plant Parts by HPTLC. Journal of Pharma- 
cognosy and Phytochemistry, 7, 892-897.

[24] Gupta, P., Bala, M., Gupta, S., Dua, A., Dabur, R., Injeti, E., et al. (2016) Efficacy and Risk Profile of Anti-Diabetic Therapies: Conventional vs Traditional Drugs-A Mechanistic Revisit to Understand Their Mode of Action. Pharmacological Research, 113, 636-674. https://doi.org/10.1016/j.phrs.2016.09.029

[25] Shadung, K.G. (2016) Quality Protocols for Nemarioc-AL and Nemafric-BL Phytonematicides and Potential Chemical Residues in Tomato Fruits. University of Limpopo, Limpopo.

[26] Kemunto, O.L. (2015) Operations Management and Performance of Kenya Tea Development Agency Managed Tea Factories in Kenya. University of Nairobi, Nairobi.

[27] Mose, M.T., Ochanda, S.O., Moseti, K., John Kanyiri, W., Philip, O., Kangethe Kinyua, J., et al. (2019) Catechins and Plain Black Tea Parameters Variations in Selected Tea Growing Agro-Ecological Zones in Kenya.

[28] Chandrajith, R., Nanayakkara, S., Itai, K., Aturaliya, T.N.C., Dissanayake, C.B., Abeysekera, T., et al. (2011) Chronic Kidney Diseases of Uncertain Etiology (CKDue) in Sri Lanka: Geographic Distribution and Environmental Implications. Environmental Geochemistry and Health, 33, 267-278.

https://doi.org/10.1007/s10653-010-9339-1

[29] Adhikari, U., Nejadhashemi, A.P. and Woznicki, S.A. (2015) Climate Change and Eastern Africa: A Review of Impact on Major Crops. Food and Energy Security, 4, 110-132. https://doi.org/10.1002/fes3.61

[30] El-Ramady, H.R., Domokos-Szabolcsy, É., Abdalla, N.A., Taha, H.S. and Fári, M. (2015) Postharvest Management of Fruits and Vegetables Storage. In: Lichtfouse, E., Ed., Sustainable Agriculture Reviews, Vol. 15, Springer, Cham, 65-152. https://doi.org/10.1007/978-3-319-09132-7_2

[31] Muthumani, T., Verma, D.P., Venkatesan, S. and Senthil Kuman, R.S. (2013) Influence of Climatic Seasons on Quality of South Indian Black Teas. Journal of Natural Product and Plant Resources, 3, 30-39.

[32] Owuor, P.O. et al. (2011) Effects of Genotype, Environment and Management on Yields and Quality of Black Tea. In: Lichtfouse E., Ed., Genetics, Biofuels and Local Farming Systems, Vol. 7, Springer, Dordrecht, 277-307.

https://doi.org/10.1007/978-94-007-1521-9_10

[33] Pripdeevech, P., Rothwell, J., D’Souza, P.E. and Panuwet, P. (2017) Differentiation of Volatile Profiles of Thai Oolong Tea No. 12 Provenances by SPME-GC-MS Combined with Principal Component Analysis. International Journal of Food Properties, 20, S2450-S2462. https://doi.org/10.1080/10942912.2017.1374288

[34] Hall, R.D. (2018) Plant Metabolomics in a Nutshell: Potential and Future Challenges. In: Roberts, J.A., Ed., Annual Plant Reviews Online, Vol. 43, 1-24. https://doi.org/10.1002/9781119312994.apr0461

[35] Shi, Y., Wu, H., Wang, C., Guo, X., Du, J. and Du, L. (2016) Determination of Polycyclic Aromatic Hydrocarbons in Coffee and Tea Samples by Magnetic Solid-Phase Extraction Coupled with HPLC-FLD. Food Chemistry, 199, 75-80. https://doi.org/10.1016/j.foodchem.2015.11.137

[36] Baiano, A. (2014) Recovery of Biomolecules from Food Wastes-A Review. Molecules, 19, 14821-14842. https://doi.org/10.3390/molecules190914821

[37] Tan, S.P., Parks, S.E., Stathopoulos, C.E. and Roach, P.D. (2014) Extraction of Flavonoids from Bitter Melon. Food and Nutrition Sciences, 5, 458-465. https://doi.org/10.4236/fns.2014.55054 
[38] Ignat, I., Volf, I. and Popa, V.I. (2011) A Critical Review of Methods for Characterisation of Polyphenolic Compounds in Fruits and Vegetables. Food Chemistry, 126, 1821-1835. https://doi.org/10.1016/j.foodchem.2010.12.026

[39] Khoddami, A., Wilkes, M.A., and Roberts, T.H. (2013) Techniques for Analysis of Plant Phenolic Compounds. Molecules, 18, 2328-2375.

[40] MAP, S.A.E. (1985) MAP 1572 I. Dimensions, 7, Article No. 875.

[41] Refaat, J., Desoukey, S.Y., Ramadan, M.A. and Kamel, M.S. (2015) Rhoifolin: A Review of Sources and Biological Activities. International Journal of Pharmacognosy, 2, 102-109.

[42] Panche, A.N., Diwan, A.D. and Chandra, S.R. (2016) Flavonoids: An Overview. Journal of Nutritional Science, 5, Article No. e47. https://doi.org/10.1017/jns.2016.41

[43] Miao, M., Jiang, B., Jiang, H., Zhang, T. and Li, X. (2015) Interaction Mechanism between Green Tea Extract and Human $\alpha$-Amylase for Reducing Starch Digestion. Food Chemistry, 186, 20-25. https://doi.org/10.1016/j.foodchem.2015.02.049

[44] Kicel, A. and Olszewska, M.A. (2015) Evaluation of Antioxidant Activity, and Quantitative Estimation of Flavonoids, Saponins and Phenols in Crude Extract and Dry Fractions of Medicago lupulina Aerial Parts. Natural Product Communications, 10, Article ID: 1934578X1501000326. https://doi.org/10.1177\%2F1934578X1501000326

[45] Khan, N. and Mukhtar, H. (2013) Tea and Health: Studies in Humans. Current Pharmaceutical Design, 19, 6141-6147. https://doi.org/10.2174/1381612811319340008

[46] Punyasiri, P.A.N., Jeganathan, B., Dananjaya Kottawa-Arachchi, J., Ranatunga, M.A.B., Abeysinghe, I.S.B., Kumudini Gunasekare, M.T., et al. (2017) Genotypic Variation in Biochemical Compounds of the Sri Lankan Tea (Camellia sinensis L.) Accessions and Their Relationships to Quality and Biotic Stresses. The Journal of Horticultural Science and Biotechnology, 92, 502-512.

https://doi.org/10.1080/14620316.2017.1289070

[47] Peterson, J.J., Dwyer, J.T., Jacques, P.F. and McCullough, M.L. (2012) Associations between Flavonoids and Cardiovascular Disease Incidence or Mortality in European and US Populations. Nutrition Reviews, 70, 491-508.

https://doi.org/10.1111/j.1753-4887.2012.00508.x

[48] Luximon-Ramma, A., Bahorun, T., Crozier, A., Zbarsky, V., Datla, K.P., Dexter, D.T., et al. (2005) Characterization of the Antioxidant Functions of Flavonoids and Proanthocyanidins in Mauritian Black Teas. Food Research International, 38, 357-367. https://doi.org/10.1016/j.foodres.2004.10.005

[49] Owuor, P.O., Kamau, D.M. and Jondiko, E.O. (2010) The Influence of Geographical Area of Production and Nitrogenous Fertiliser on Yields and Quality Parameters of Clonal Tea. Journal of Food, Agriculture \& Environment, 8, 682-690.

[50] Samanta, T., Cheeni, V., Das, S., Roy, A.B., Ghosh, B.C. and Mitra, A. (2015) Assessing Biochemical Changes during Standardization of Fermentation Time and Temperature for Manufacturing Quality Black Tea. Journal of Food Science and Technology, 52, 2387-2393. https://doi.org/10.1007/s13197-013-1230-5

[51] Del Rio, D., Stewart, A.J., Mullen, W., Burns, J., Lean, M.E.J., Brighenti, F., et al. (2004) HPLC-MS ${ }^{n}$ Analysis of Phenolic Compounds and Purine Alkaloids in Green and Black Tea. Journal of Agricultural and Food Chemistry, 52, 2807-2815. https://doi.org/10.1021/jf0354848

[52] Lv, H., Zhang, Y., Lin, Z. and Liang, Y. (2013) Processing and Chemical Constitu- 
ents of Pu-erh Tea: A Review. Food Research International, 53, 608-618. https://doi.org/10.1016/j.foodres.2013.02.043

[53] Formisano, C., Delfine, S., Oliviero, F., Tenore, G.C., Rigano, D. and Senatore, F. (2015) Correlation among Environmental Factors, Chemical Composition and Antioxidative Properties of Essential Oil and Extracts of Chamomile (Matricaria chamomilla L.) Collected in Molise (South-Central Italy). Industrial Crops and Products, 63, 256-263. https://doi.org/10.1016/j.indcrop.2014.09.042

[54] Kfoury, N., Morimoto, J., Kern, A., Scott, E.R., Orians, C.M., Ahmed, S., et al. (2018) Striking Changes in Tea Metabolites Due to Elevational Effects. Food Chemistry, 264, 334-341. https://doi.org/10.1016/j.foodchem.2018.05.040

[55] Nyabundi, K.W., Owuor, P.O., Netondo, G.W. and Bore, J.K. (2019) Fertilizer Response and Environment Interactions of Yield and Yield Components of Clonal Tea (Camellia Sinensis) in Kenya. International Journal of Tea Science, 141, 7-13. 